\title{
GPAs, PCATs, and Coupons: Wilting Quality in Pharmacy School Admissions and the Impact on Pharmacy Faculty
}

Sara A. Thompson, PharmD, BCACP

North Dakota State University School of Pharmacy

\begin{abstract}
Introduction: The number of available seats in US pharmacy schools has reached unprecedented numbers as applications are on the decline. A combination of forces signals that admissions to pharmacy school are becoming less selective.

Commentary: The conflict of balancing a need to fill the incoming class while maintaining selectivity is a growing problem in pharmacy education. Faculty may notice changes in the student quality and ultimately, program and graduate quality. Pressure from administration hinders faculty governance with negative consequences that impact faculty morale and the profession as a whole. Maintaining a firm position in the face of reduced applications is challenging but necessary if we are to protect the students we seek to support as faculty and stewards of the pharmacy profession.

Implications: Faculty governance is at risk as pressure exists to admit less-prepared students into programs. Faculty must advocate for responsible leadership by initiating dialogue on admissions and selectivity. Furthermore, faculty mentorship programs need a new level of discussion that includes analysis and understanding of this paradigm in pharmacy academia.
\end{abstract}

Keywords: Admissions, enrollment, faculty governance, student advocacy

\section{Introduction}

The pipeline for pharmacy school applicants is drying up. The number of Doctor of Pharmacy (PharmD) programs has dramatically increased over the past several years and existing programs have increased class sizes, leading to a corresponding doubling of pharmacy degrees conferred. ${ }^{1}$ To further complicate matters, acceptance rates for pharmacy school admissions have skyrocketed to $82.9 \%$ for the application cycle of 2018-2019. ${ }^{2}$ This is accompanied by a decreasing overall grade point average (GPA) among applicants, with the average science GPA seeing the largest drop from 3.34 to 3.15 over the past several years. ${ }^{2}$ Admissions offices and administration must continue to entice and admit students with this level of academic preparation to keep the doors open on the plethora of pharmacy schools. For the 2019-2020 admissions cycle, schools could purchase and offer application coupons to "incentivize" candidates to apply. ${ }^{3}$ Discussion for reducing prerequisites for pharmacy programs also exists as a reactionary effort. ${ }^{4}$ These factors combined, admission to a pharmacy program, once an accomplishment, is now a near guarantee as a result of dwindling selectivity. ${ }^{2}$ In other words, we are admitting students into PharmD programs today that would have hardly been considered a few years ago. Faculty members are faced with the challenge of teaching in an era where schools are becoming less selective in order to fill seats. Furthermore, administrative teams may place undue pressure on faculty that disrupt governance, especially with admissions. Faculty must confront the dissonance of maintaining quality standards while under pressure to prepare students with less

Corresponding author: Sara A. Thompson, PharmD, BCACP

Assistant Professor

North Dakota State University School of Pharmacy

1340 Administration Ave., Fargo, ND 58105

Phone: 701-231-7502; Email: sara.a.thompson@ndsu.edu robust academic backgrounds for the profession of pharmacy. There is a paucity of guidance for faculty that find themselves in this predicament.

\section{Commentary}

As colleges of pharmacy struggle to meet enrollment targets, faculty may begin to see signs of discord between the studentcentered focus of a program and the day-to-day operations of the institution. For example, the mission of a program that is "student-centered" could reasonably be interpreted to mean a program would ensure candidates are prepared for the academic rigors of a PharmD program. If instead decisions by key committees (e.g. admissions) are made not in the best interest of the student, or worse yet, if those decisions are overturned, faculty will realize the governance of the school, and consequently their ability to support student success, is undermined.

There is a necessary balance between maintaining selectivity in pharmacy school admissions and ensuring the fiscal health of a program. Many faculty, especially early career, have little to no experience in administration and cannot truly appreciate the financial implications of not filling the projected student capacity on which a budget is based. Also, it is unreasonable to expect that administration will accept every decision of the admissions, or any, committee without contest. However, when the balance swings too far one way, faculty lose their voice and sense of self-governance.

Administration should be cautious when attempting to minimize the connection between admitting students with poor academic foundations, student retention rates, and the overall well-being of the institution. Furthermore, interference from administration regarding faculty decisions on admissions and progression should be minimized. Unfortunately, this 
autonomy cannot be guaranteed as schools become dangerously less selective in the current era of a surplus of pharmacy graduates. What does this reality mean for faculty, administration, and the profession as a whole? As recently noted by Lebovitz and Eddington, pharmacy schools are focusing on squeezing dry the wet rag of pharmacy school applications while the mean number of applications per school has been nearly cut in half over the last several years. ${ }^{5}$ Hopefully early career and veteran faculty will not face dilemmas similar to those outlined here; however, with the current landscape in the academy and the market being unlikely to reverse course quickly, faculty will likely face this problem with greater frequency than ever before.

The professional community has raised concerns over this perfect storm via a petition on change.org, and the academy's leadership felt compelled to respond to the strife. American Association of Colleges of Pharmacy executive vice president and CEO Lucinda Maine recently addressed this simmering disquietude in our profession and the question of "too many schools?" by answering ${ }^{6}$ :

"Changes in both education and practice must accelerate to more effectively position pharmacists in a wide variety of settings to deliver on the promise of their education. Pharmacy educators and practitioners also need to address gaps in knowledge through research to ensure that new and old pharmaceutical products are available and used in the most effective manner to prevent and resolve medication-related problems."

Unfortunately, this answer circumvents the essential dilemma. The problem is not what we are teaching. The availability of "pharmaceutical products" fails to address the issue of too many schools, insufficient applications to allow selectivity in our profession and the maintenance of high standards for incoming students. The leadership in the academy should encourage the establishment of trust between administration and faculty. That trust can take the form of encouraging faculty to be vocal in sharing their perspective and input as pharmacy programs shape the future of the profession.

\section{Implications}

Faculty in all ranks and disciplines must define their position on this issue before the situation worsens. The choice remains between inactivity and action. Faculty and administration must look past the immediate tuition dollars to see the long-term vision. Focus has been on increasing enrollment via measures such as reducing prerequisites, eliminating the PCAT, and providing application coupons as incentives. ${ }^{3,4}$ However, there are consequences to this short-sightedness of simply trying to maintain or increase numbers. As posited in a debate at the Academic Leadership Fellows Program (ALFP) in 2017, “...taking aggressive action to prevent further declines in enrollment...will eventually come at the cost of competent graduates." 1
In a study by Desselle and Conklin in 2005, quality of students in the program was positively associated with job satisfaction among pharmacy faculty. ${ }^{7}$ If it was possible for high student quality to improve job satisfaction, student quality is an aspect administration should seek to protect as they advocate for the faculty and profession. Schools need to heighten efforts to attract and attain quality applicants through unique, multifaceted approaches that include intentional admissions strategies that connect quality applicants to the school throughout the process. ${ }^{8}$ Faculty may consider engaging in the admissions process throughout the academic year in order to not only interact with applicants but also to maintain abreast of the formation of the incoming class. This goes beyond merely boosting numbers for the sake of the bottom line.

The professional organizations that represent us should rethink their strategy to passively observe the opening of more pharmacy schools. While it is clear that anti-trust laws do not permit the prevention of pharmacy schools from opening, we can establish a coalition of stakeholders to assess and lobby for responsible management of the landscape of pharmacy education. ${ }^{1}$ Simply "monitor[ing] the dynamics of enrollment" and remaining stagnant since there is "no one solution" is not enough. ${ }^{9}$ We have known about this crisis for years, yet little has been done. ${ }^{10}$ Waiting for the academy's leadership to guide us is unlikely to completely resolve the issues locally. The faculty voice can, however, effectively advocate for responsible leadership in our profession by initiating continued dialogue on admissions practices and advocating for selectivity. Furthermore, it is time that faculty and administration rethink the resistance towards reducing class sizes. The positive impact of reducing the class size far outweighs the temporary negative of budget readjustment. ${ }^{5}$ These solutions require a long-term vision to pharmacy education.

Finally, mentorship and development of faculty needs a new layer of development to navigate the current trends in pharmacy schools. In a preparing future faculty program description, a comprehensive list of objectives includes the traditional teacher training tasks, such as preparation of a teaching philosophy. ${ }^{11}$ However, it lacks training on how to handle dissonance between the vision for a profession and the immediate needs of a school. Furthermore, as students with less academic preparedness are admitted to pharmacy schools, faculty may need additional professional development opportunities to better teach students with different foundations.

Change takes time, and this is one piece of a complicated puzzle of challenges in pharmacy academia. It is incumbent on those in pharmacy academia to participate in the changing landscape in order to provide a brighter future for our students. In the meantime, we can learn from the stories of each other and remind ourselves to fight in the best interest of those we ultimately work for: the students. 
Acknowledgements: None

Funding/support: None

Conflict of Interests: None

\section{References}

1. Pavuluri N, Aparasu RP, Boje KMK, et al. Consideration of aggressive and strategic approaches to address declining enrollment in US pharmacy schools. Am J Pharm Educ. 2019;83(6): Article 6959. doi: 10.5688/ajpe6959

2. American Association of Colleges of Pharmacy. PharmCAS Applicant Data Report. 2018-2019. Available at:

https://connect.aacp.org/HigherLogic/System/Downloa dDocumentFile.ashx?DocumentFileKey=6fd0bf77-20d68bd0-ea8f-802291427396. Accessed September 18, 2020.

3. Bruce K. Coupon codes now available in PharmCAS. Available at: https://connect.aacp.org/communities/groupdetails/dig estviewer/viewthread?MessageKey=33b604df-14ca4387-ba4c-13605a34465c\&CommunityKey=aeb59d450cea-44ef-8060-

29508a5725eb\&tab=digestviewer\#bm33b604df-14ca4387-ba4c-13605a34465c. Accessed September 18, 2020.

4. Pate A. Is it time to decrease preprofessional pharmacy requirements? Am J Pharm Educ. 2015;79(8): Article 110. doi: 10.5688/ajpe798110.

5. Lebovitz L, Eddington ND. Trends in the pharmacist workforce and pharmacy education Am J Pharm Educ. 2019;83(1): Article 7051. doi: 10.5688/ajpe7051.

6. Maine LL. It really isn't that simple. Am J Pharm Educ. 2019;83(4):Article 7593. doi:10.5688/ajpe7593.

7. Desselle SP, Conklin MH. Predictors of pharmacy faculty work satisfaction. Curr Pharm Teach Learn. 2010;2(1):20-30. doi: 10.1016/j.cptl.2009.12.003

8. Curti SD, Feild, C, Buring SM. Improving admissions outcomes through the use of a task force on recruitment, admissions and retention. Am J Pharm Educ. 2019; 83(9): Article 7307. doi: 10.5688/ajpe7307

9. American Association of Colleges of Pharmacy. Response to changepharmacy.org petition. Available at: https://www.aacp.org/article/joint-responsepetitioners-seeking-moratorium-accreditation-newpharmd-institutions. Accessed September 18, 2020.

10. Brown DL. A looming joblessness crisis for new pharmacy graduates and the implications it holds for the academy. Am J Pharm Educ. 2013;77(5): Article 90. doi: 10.5688/ajpe77590

11. Medina MS, Tomasek JJ, Bowers-Pippin J. The use of mentors and partnerships in a preparing future faculty program at a health sciences center. Curr Pharm Teach Learn. 2015;7(2):145-150. doi: 10.1016/j.cptl.2014.11.008 